\title{
Thick Roofs: Technological Containment and Symbolic Form
}

\author{
MICHELLE CHANG \\ Rice University
}

The roof is one of architecture's primary constituent elements. Whether its origins stem from functional, moral, or political purposes in uncertain, but the design of roofs has historically engaged form with performance. In Laugier's account of the primitive hut, the roof was created to shield humans from nature; Semper contends that it came about to protect the hearth; and Koolhaas suggests that, from the beginning, roofs were made to signify power. ${ }^{1}$ Though these origin stories leave out the complex relationships between cultural, economic, and technical contexts, their reductive clarity serves as a lens for judging architectural qualities of scale, shape, and proportion.

These formal questions fundamentally changed at the turn of the $19^{\text {th }}$ century when advancements in construction technologies made thin and flat material systems viable. The plane, in the form of pre- and post-tensioned slabs, stronger steel frames, and pre-cast panels, freed architecture from some of the financial and programmatic constraints that came with formal specificity. With the standardization of flat and thin parts, the formal qualities of the roof became increasingly synonymous with those of the floor plate. This shift opened up the possibility for Le Corbusier to translate a roof deck into a park at the Unite d'Habitation and for Mies to connect the Bacardi Office Building with Cuba's infinite horizon. However, as the roof became an upward succession of the floor, many architectural components had to find somewhere else to hide. $^{2}$

A hypothesis of this paper is that the fragmentation of building parts in contemporary architecture stems from perpetuating building conventions from post-WWI construction technologies. The invention of load-bearing frames and reinforced concrete made systems like the Maison Dom-ino possible. However, as the design of facades and plans were freed from structure, the design of roofs became entangled in what had previously been the obligations of floor plates (i.e. flatness). The conceptual clarity of modernism's total building systems, coupled with evolving environmental and security standards in the present day, have necessitated the design of architectural exceptions. A building's integral components, like MEP and HVAC, are regularly designed as elements that sit proud of a coherent envelope. This paper investigates ways these detached parts can be conceptually and materially absorbed into a single volumetric roof.

Figure 1: Google image screen capture of (clockwise from top): Palace of the Assembly, Martin Luther King Jr. Memorial Library, Unité d'habitation, Crown Hall, Chicago Federal Center

If we consider the possibility that the paradigm that once liberated façade design, plan, programming, and space is out-of-date, what new framework can accommodate contemporary architectural demands? If being thin is no longer viable, how can architecture engage models of thickness?

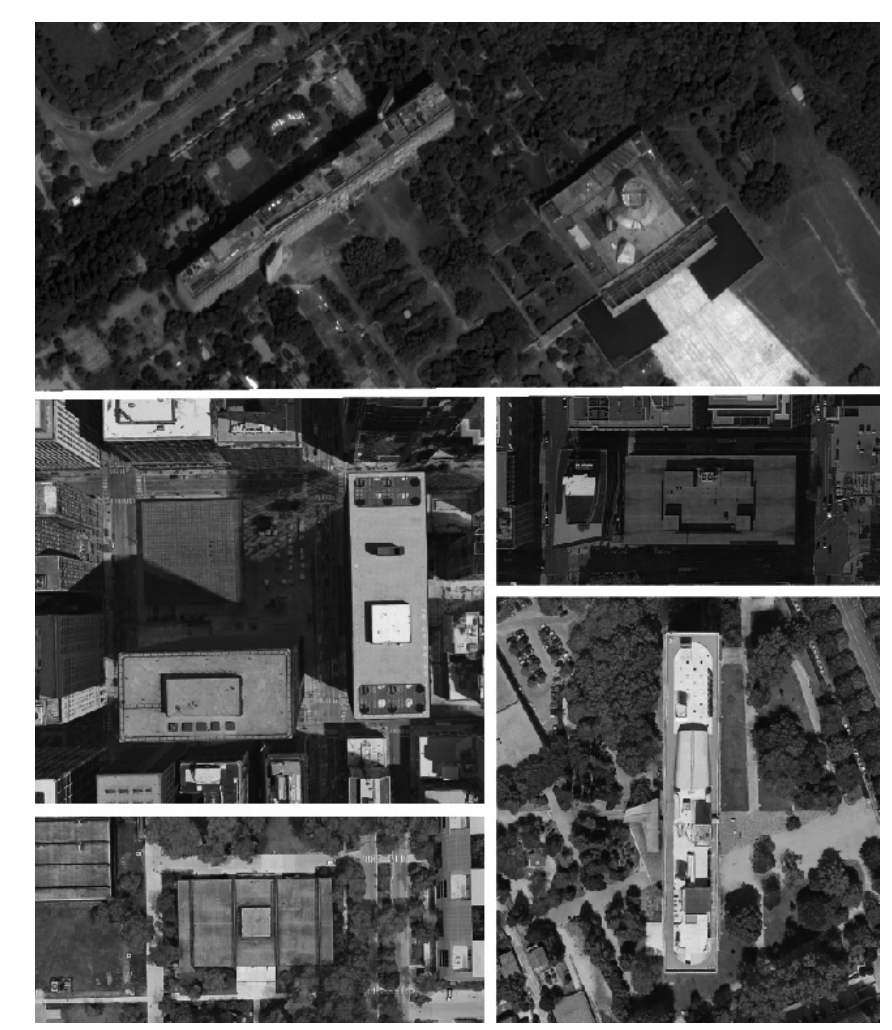

\section{ARCHITECTURAL EXCEPTIONS FROM}

Looking at the aerial view that Google Maps affords us reveals how often air handling or other mechanical units protrude the John C. Kluczynski Federal Building shc a thick roof, these parts are concealed by shying away from other modern technological components collected on rooftops (figure 1). 


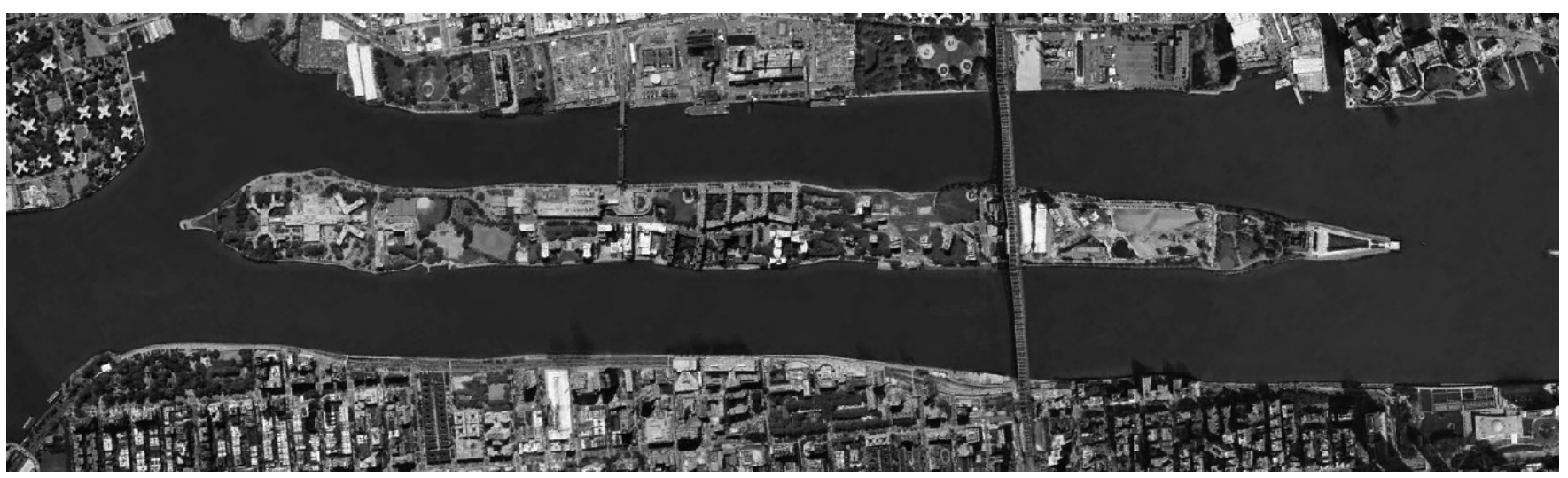

Figure 2: Google image screen capture of Roosevelt Island. Site location in red.

\section{COURSE WORK}

In the fall of 2017, I taught a studio on the topic of thick roofs at Rice University. ${ }^{3}$ The course was a comprehensive studio, known as "Totalization," taught in the terminal year of the school's BArch and MArch program. Sited in Roosevelt Island's South Point Park, the building project was to design a visitor center containing a lobby, restaurant, and restrooms. The seven-acre park is wedged between Louis Kahn's FDR Four Freedoms Park and the recently developed Cornell Tech Campus. Because of the site's location on the East River, the project's roof is visible to the adjacent buildings, to the tramway, and to several Manhattan high-rises across the river (figure 2).

The design project was structured around a set of six problems:

1. In what ways can thick roofs mediate a building's image and its surrounding environment?

2. If flat and thin are no longer virtues in the design of a roof section, what criteria for evaluation can architects use to detail?

3. How can architectural movements from history inform strategies for thickening? In particular, what does the shift from Renaissance lightness to Baroque massiveness show us?

4. What are methods for absorbing a building's technical components and services into a thick roof?

5. What is a formal system for cutting holes (doors, diffusers, lights, skylights, windows) into a singular form?

6. How can contemporary and historical representational modes spur design strategies?

Students developed their designs for a visitor center by negotiating the demands of these formal and conceptual problems and the advice of four consultants: Robert Heintges
(Heintges, building envelope and curtain wall consultants, NYC), Nat Oppenheimer and Pat Arnett (Silman, structural engineer consultants, NYC), and Mark Malekshahi (Plus Group, MEP consultant, NYC). In each case, the architectural components introduced in the project's mid and late stages created opportunities for fullness. The techniques invented to integrate water collection, water runoff, passive heating and cooling devices, among others were constrained by aesthetic principles, and vice versa. The oscillation between these modes was productive in imagining the potentials for new building systems.

A fundamental question raised over the course of the studio was how to negotiate a surplus of form. I would like to suggest that this problem brought on by technological necessity (e.g. sustainability and surveillance requirements) has a formal solution that creates a symbolic potential for architecture. To investigate one path forward, we can look to Heinrich Wölfflin's writing on massiveness and symbolization.

\section{WÖLFFLIN'S MASSIVENESS}

Wölfflin's associations between massiveness and affect provide useful criteria to investigate how thickened roofs can act as symbolic forms. First, massive architecture exhibits fullness, thus making its formal characteristics favorable for enveloping architectural parts. ${ }^{4}$ Second, the aesthetic perception of massive architecture introduces a vicarious response, or an affect, which Wölfflin attributes to form's symbolization. In his writing, Wölfflin establishes evaluative principles for both massive form and its aesthetic effects.

In Renaissance and Baroque, Wölfflin unpacked the term massiveness through a distinction between baroque and renaissance styles. In baroque forms, the proportion between architectural elements in a building's overall composition is compressed to give the impression of heaviness. For example, Giacomo della Porta's design of the Church of the Gesù implements a tall attic floor and short pedestals to give the sense of "weight and oppressiveness." ${ }^{5}$ These 
affective qualities - heaviness, broadness, and fullness - seen in baroque forms are perceptible because of a visual and conceptual comparison to renaissance forms. Pediments appear shallow, pedestals look flattened, and other architectural elements seem to spread widely when related to the horizontal and vertical proportions in previous styles.

Along with the apparent heaviness suggested by Baroque architecture's diminished proportions, Wölfflin observed that a loss of building articulation created the perception of softness. In what Wölfflin called a "lack of precision," tectonic expression disappeared in the baroque style. Edges became more visually inconspicuous as the practice of framing corners disappeared. ${ }^{6}$ As an example, Wölfflin compares the walls in the Palazzo della Cancelleria to those in the Palazzo Farnese. Whereas in the former, walls exhibit exposed stones to express their discrete parts, in the latter, walls are covered in a layer of stucco, obscuring their material makeup. The fine detail and tectonic expression found in the renaissance style was smoothed out and replaced with ruder forms.

\section{WÖLFFLIN'S AESTHETIC PRINCIPLES AND THE NOTION OF AFFECT FROM VISCHER'S SYMBOLIC FORM}

"The human mind is sufficiently active to be reminded of... resemblances between external things and its own mental states, experiences, sensations, moods, emotions, and passions. It finds in everything a counterpart to itself and a symbol of its humanity." -Robert Vischer

"The anthropomorphic apprehension of three-dimensional forms... has come to be known as symbolizing." -Heinrich Wölfflin

Written two years before Renaissance and Baroque, Wölfflin described the effects of massiveness in his 1886 dissertation, Prolegomena to a Psychology of Architecture. Borrowing principles from Robert Vischer's writing on aesthetics and empathy theory, Wölfflin ties architectural composition to the organization of the human body. ${ }^{9}$ Under this logic, form becomes symbolized through our process of relating the two systems to each other.

He begins his thesis with a fundamental question, "How is it possible that architectural forms are able to express an emotion or a mood?" To Wölfflin, the aesthetic perception of matter and form, gravity, and force are palpable through our familiarity with our own bodies. We respond vicariously to architecture because it conveys familiar material, formal, and gravitational traits. In other words, our aesthetic judgment of architecture is through a comparison to the human physique. Symbolic form arises when a formal expression, like a façade, imparts an impression, or a mood, onto a subject.
Architectural forms convey moods through our judgment of their aesthetics; and this judgment is informed by a set of intrinsic laws governing bodily forms. Wölfflin unpacks these formal laws with the aid of principles previously developed by Friedrich Vischer in $1873 .{ }^{10}$ In Prolegomena..., he expands on the ways Vischer's formal categories - regularity, symmetry, proportion, and harmony - provoke affects. He suggests that not all architecture is equally capable of acting as symbolic form; rather architectural symbolization requires formal similarities between objects and bodies. ${ }^{11}$ For example, he argues that asymmetrical forms are capable of conveying discomfort because they reference bilateral symmetry and thus are suggestive of disfigured bodies. Like his comparison between renaissance and baroque styles, Wölfflin establishes a set of moods in reference to a standard. Whereas renaissance style is the norm with which baroque forms are judged, the regular, symmetrical, well proportioned, and harmonious human body is the foil for judging affects.

While Wölfflin's morphological claims are arguable, his aesthetic criteria for judging psychological affects are nevertheless productive for establishing a contemporary total building system. Today's technological demands precipitated by enhanced security and acclimatization codes muddy the conceptual clarity of Modernism's total building system. By sitting proud of a technologically efficient envelope, the HVAC units, antennas, solar panels and other components act as architectural exceptions. These exceptions arising from overlaying modern building codes onto Modernism's $20^{\text {th }}$ century paradigm undermine Modernism's ethos in which form is an expression of function.

To evolve Modernism's total building system into a $21^{\text {st }}$ century context requires alternative frameworks that consider formal and conceptual strategies. Rather than propose a techno-material paradigm in which new elements are reabsorbed into a modernist style, I would like to suggest that there are advantages in allowing some architectural elements to become more full. This paper proposes that the criteria outlined in Wölfflin's Renaissance and Baroque is an alternative formal logic to judge contemporary roofs, and the ideas expressed in his thesis offer a sympathetic conceptual framework. His ideas on the symbolic form offer a method with which to aesthetically judge contemporary architecture. This model considers the capacity for roof forms to create psychological effects rather than its former abilities to convey political power or shelter.

\section{CONTEMPORARY THICK ROOFS}

There are a few contemporary projects that how affective form can be married with a thick technological roof. OMA's McCormick Tribune Campus Center (2003) and Jean Nouvel's Philharmonie de Paris (2015) are notable examples of contemporary thick roofs because they display Wölfflin's notion of massiveness and the absorption of technical components 


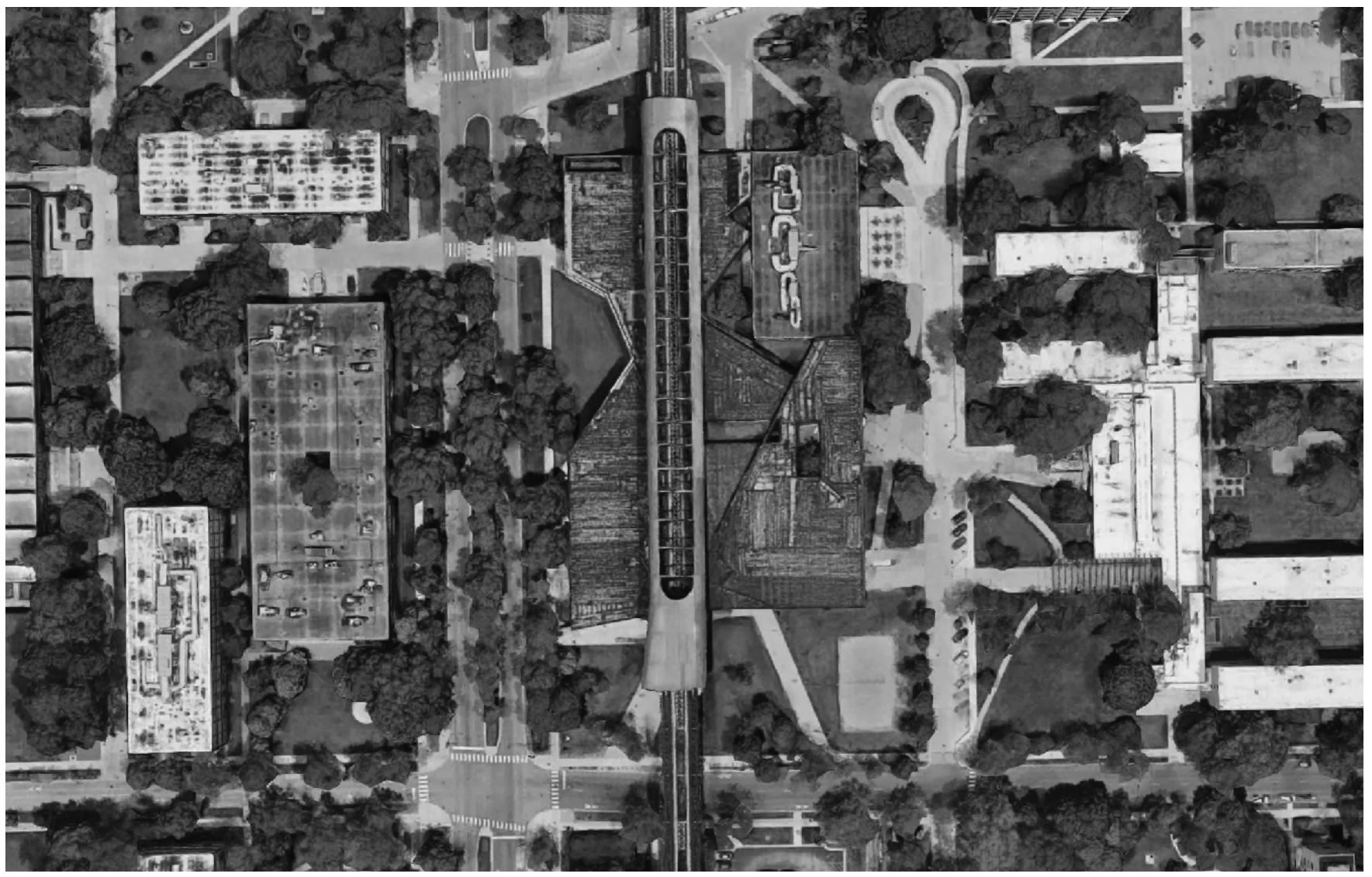

Figure 3: Google image screen capture of OMA's McCormick Tribune Campus Center

into thickened envelopes.

The McCormick Tribune Campus Center: OMA's McCormick Tribune Campus Center creates an affective response with its roof while absorbing elements that might otherwise sit proud of its envelope. Set in the Illinois Institute of Technology campus designed by Mies van der Rohe, the building's form references its surrounding context. Unlike the nearby buildings (figure 3), the McCormick Tribune Campus Center is free of mechanical units on its roof.

The roof of OMA's McCormick Tribune Campus Center is an example of contemporary massiveness because the relationship among its parts exhibit the broadness (proportion), fullness (scale), and amorphousness (shape) characteristic to Wölfflin's definition. The building achieves the affective qualities of massive form by integrating its technological components into a cohesive wrapper.

First, the roof exhibits amorphousness because its profile appears to stretch under its own weight. In a similar manner to which the Palazzo dei Conservatori plan reveals an implied force between a column and a wall, the campus center's section conveys the weight of the Exelon Tube onto its roof plate (figure 4). Inspecting the horizontal roof plate in section and elevation reveals that the fascia shortens from the building's east and west perimeter to its middle. The fascia in the area under the Exelon Tube is shortest, suggesting that the figuration of the plate is contingent to the position of the tube. The building's lateral section reveals that the tube is ovoidal, resting on ten tapered columns. This relationship similarly suggests a downward force as an oval is a scalar vertical transformation of a circle (as opposed to an ellipse) and the columns widen towards the ground. ${ }^{12}$ In comparison to the orthogonal geometry in the surrounding buildings, the campus center's form appears to soften under its own weight.

Second, the building's roof exhibits fullness because the absorption of the tube into its roof system makes it larger than a typical roof. One reading of the project would distinguish the tube from the roof system because it is materially and geometrically dissimilar to the horizontal plate below. The tube appears to be a self-contained steel surface separate from the panel-clad concrete plate. In reality, the tube protrudes into the concrete slab, with its underbelly exposed to the interior through a hole in the ceiling. At that moment, the tube acts as if it were a plug, sheltering the interior from the elements. Thus, the roof envelope is defined by both elements, as the continuity between them is required to shed water. In other words, the coordination of the tube and the plate fulfill the technical responsibilities of the roof. Third, OMA's roof shows broadness because it is proportionally 
wider than the architecture that it references. Compared to Mies van der Rohe's Crown Hall, the OMA building has a smaller width-to-height ratio.

The Paris Philharmonic: Ateliers Jean Nouvel's Paris Philharmonic is a second example of contemporary massiveness. The relative scale, proportion, and shape of its building elements express the heaviness and softness found in Baroque architecture. While its roof system does not conceal all of the building's technological components (a series of photovoltaic panels sit on top of the vertical screen wall), it integrates most of its units within a cohesive envelope.
First, the building appears amorphous because of the formal relationship between the roof, façade, and ground. Compared to the horizontal layers that form the balconies below, the roof folds dramatically downward. Concrete ramps zigzag across the roof to visually and physically connect it to the ground. The roof's faceted geometry integrates several discrete parts - roof deck, ramp, skylight, and stair - into a continuous surface. On the south side, where the roof is highest, the building façade is unlike the vertical glazing that dominates much of the building; rather, it is a blob-like form that appears to buckle under the roof's weight. The formal relationship between the roof and façade is reminiscent of the bulging

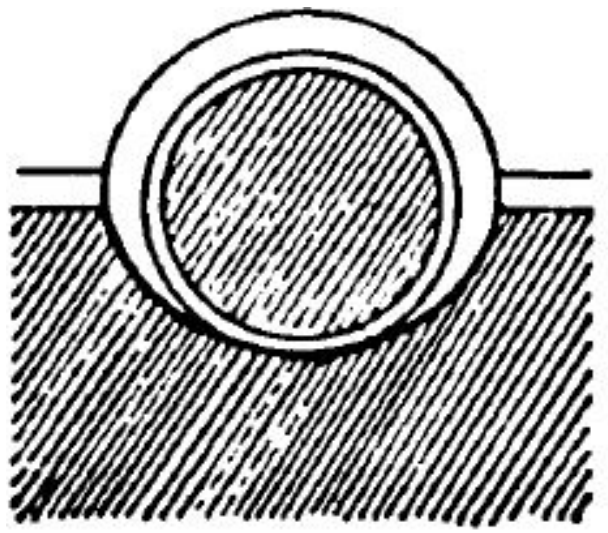

Fig. 8 Section of an
'immured' column
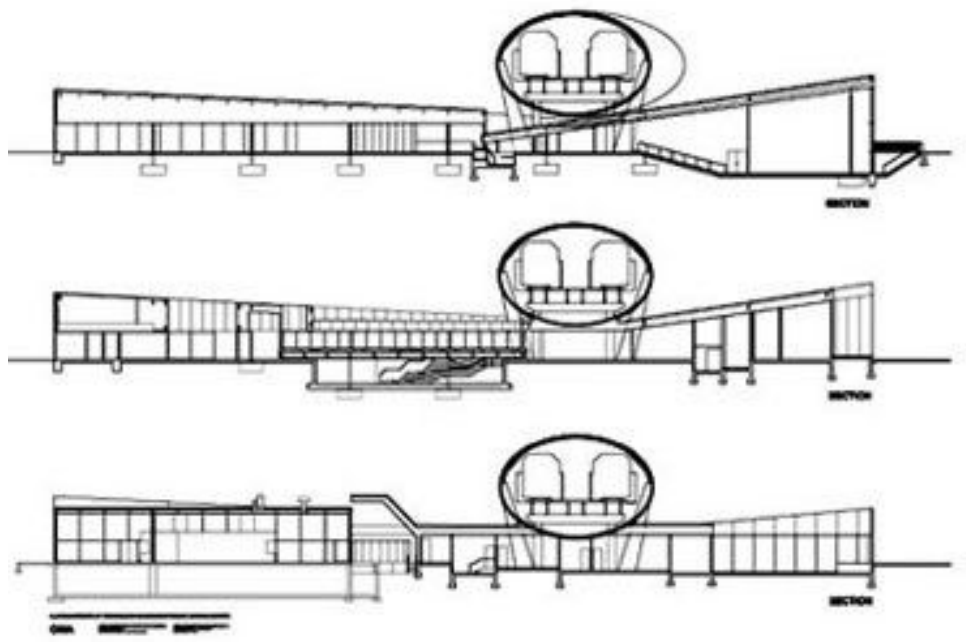

Figure 4: Sectional comparison between the colonnade at the Palazzo dei Conservatori (Wölfflin, Renaissance and Baroque, p. 52) and a lateral section through the McCormick Tribune Campus Center
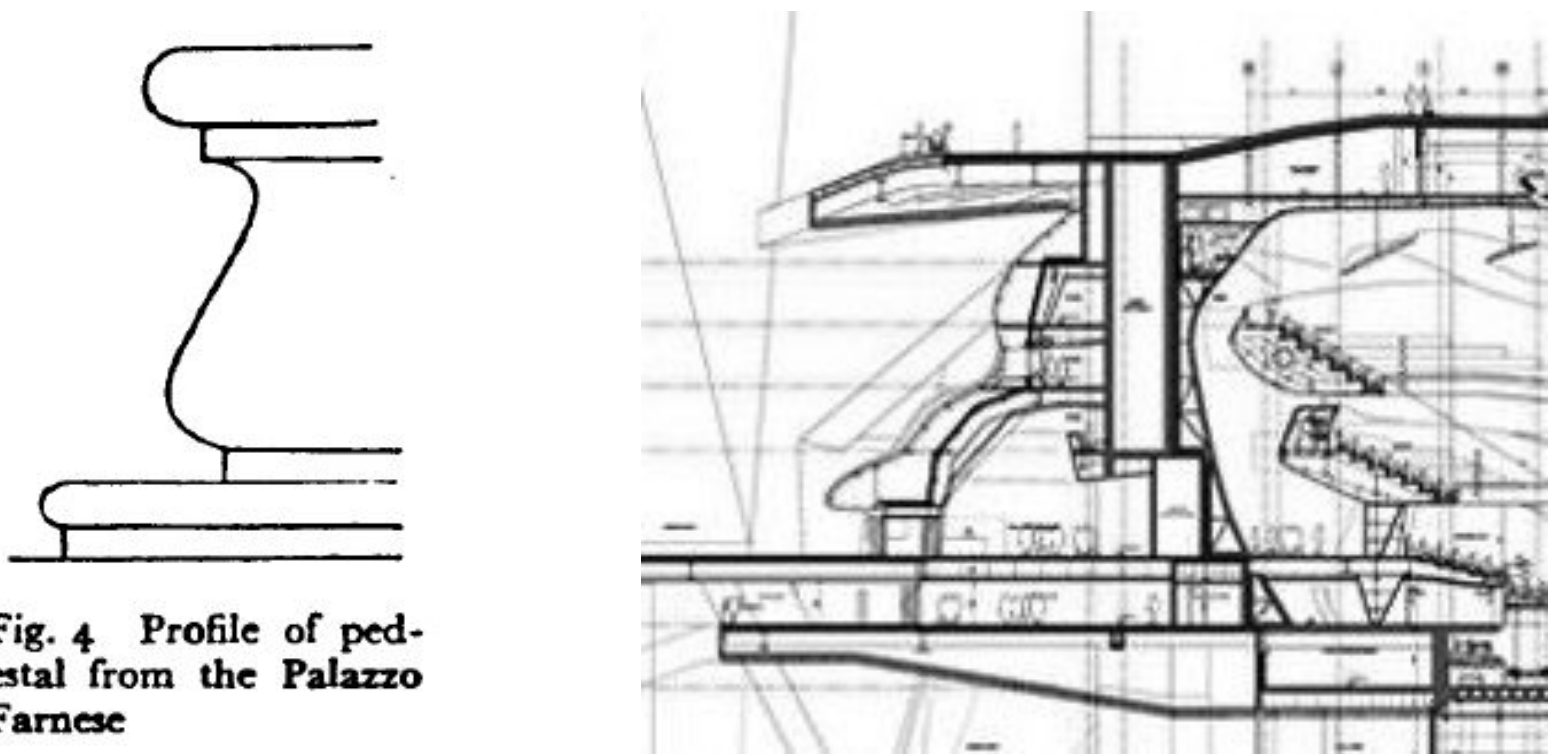

Figure 5: Comparison between the profile of Palazzo Farnese pedestal (Wölfflin, Renaissance and Baroque, p. 48) and a section through the Paris Philharmonic

Fig. 4 Profile of pedestal from the Palazzo Farnese 
pedestals at the Palazzo Farnese, as shown in a north-south section through the building's auditorium (figure 5).

Second, the roof appears full because it covers many disparate elements. The philharmonic is a multi-tiered building comprised of a 2,400-seat concert hall, offices, rehearsal rooms, and public programming. Each layer is articulated in the building massing through shifting layers in plan and changes in materiality. While much of the exterior cladding is in shades of grey, the discretization patterns switch from regular to irregular geometries across distinct volumes. For example, the screen wall is clad in aluminum bird-shaped panels and the auditorium is encased in reflective steel quad panels. Moreover, the roof covering the concert hall is uniquely formed because it houses audiovisual support spaces, large trusses, and air ducts.

Third, the building appears broad because its geometry connects to the landscape. Most of the philharmonic's programming is concentrated north of the building's vertical screen wall. However, an educational wing, offices, and an esplanade are located in a low volume on its south side. This mass slopes downward to meet the sidewalk over a length almost equal to the rest of the building. As a result, the overall building proportion widens along its eastern facade, though the south wing houses a relatively small portion of the building.

\section{CONCLUSION}

Forming a proposal for thick roofs around Wölfflin's notion of symbolism and his definition of massiveness is not merely an approach to systems integration. Rather, combining this historical framework with a contemporary formal problem investigates ways to create subjectivities with affect. This strategy builds upon the roof's symbolic history, as told in its origin stories, and its morphology. If we consider the evolving standards in the scale, shape, and proportion of architecture's elements, there is potential to engage the design of objects with their contexts. Here, recasting the conceptual clarity of a $20^{\text {th }}$ century total building system is not merely a technological concern, it is what ties this investigation to the conference topic. That is, thick and shapely roofs have the capacity to impact a broad audience with their affective images, thus making architecture instrumental in redefining public space.

\section{ENDNOTES}

1. Koolhaas, Rem, and James Westcott. n.d. Elements [of Architecture] [a series of 15 books accompanying the exhibition Elements of Architecture at the 2014 Venice Architecture Biennale]. [s.I.]: Marsilio.

2. Cohen, Preston Scott. 2014. "Successive Architecture." Log. (32): 153-163.

3. This topic was developed through teaching the course, Arch 601: Gross Roofs, at Rice Architecture. Students taking the studio included: Mark Bavoso, Gavin Brown, Stephen Collard, Daniel Kleeschulte, Sheila Mednick, Philip Nekamp, Hannah Perrino, Grey Peterson, David Rader, Sam Schuermann, and Reggie Wang.
4. Wölfflin, Heinrich, Kathrin Simon, and Peter Murray. 1994. Renaissance and Baroque. Ithaca: Cornell University Press, 47.

5. Wölfflin, Renaissance and Baroque, 44

6. Wölfflin, Renaissance and Baroque, 46

7. Vischer, Robert, Harry Francis Mallgrave, and Eleftherios Ikonomou. 1994. Empathy, form, and space: problems in German aesthetics, 1873-1893. Santa Monica, CA: Getty Center for the History of Art and the Humanities, 91.

8. Wölfflin, Heinrich. 1976. Prolegomena to a Psychology of Architecture. [Cambridge, Mass.]: [Dept. of Architecture, M.I.T.].

9. Vischer, 89-107.

10. Vischer, Friedrich. 1873. Kritik meiner Ästhetik. Stuttgart. Wiederabdruck: Kritische Gänge, Bd. 4 (1922), 222-419.

11. Wölfflin, Prolegomena to a Psychology of Architecture, 172.

12. Gargiani, Roberto, and Rem Koolhaas. 2011. Rem Koolhaas/OMA: the construction of merveilles. Lausanne: EPFL Press, 250. 